\title{
Capsule Commentary on Baier et al., A Qualitative Study of Choosing Home Health Care after Hospitalization: the Unintended Consequences of 'Patient Choice' Requirements
}

\author{
John M. Thomas, MD \\ Department of Medicine, Yale University School of Medicine, New Haven, CT, USA.
}

J Gen Intern Med 30(5):654

DOI: $10.1007 / \mathrm{s} 11606-015-3189-6$

(c) Society of General Internal Medicine 2015

$\mathrm{T}$ his study by Baier et al. ${ }^{1}$ sought to illustrate the decisionmaking process that occurs in hospital discharge planning when case managers engage with patients and families in selecting a home health agency. Case managers and home health consumers were qualitatively asked about their respective roles in the decision process, as well as their knowledge of existing public home health quality reports. No participants were aware of public quality reports. Case managers described presenting a list of available home health agencies to consumers, who in turn generally felt they had little information to guide their decision and often asked case managers for a recommendation. However, case managers felt unable to assist further in the process, citing federal laws protecting freedom of patient choice ${ }^{2}$ as preventing them from doing so.

The major limitation in this study is the unexpected fact that none of the participants were aware of public quality reporting for home health agencies, effectively truncating the discussion to observations about how uninformed the decision-making process was and conjectures about how public quality reports might be used. While it is tempting to attribute case managers' limited helpfulness in home health agency selection to the federal laws guaranteeing freedom of patient choice, the more immediate obstacle is a lack of awareness about the availability of a neutral source of quality reporting that consumers could directly access online. Other limitations include the lack of generalizability since participants were drawn solely from Rhode Island, and the relative lack of participants who were patients rather than family members.

Not to its detriment, this study raises more questions than it answers. Future work could seek to test interventions in which quality reports are provided to home health consumers prior to their selection of an agency, with various patient-level and system-level outcomes ${ }^{3}$ compared against a control. In the larger context of transitional care, ${ }^{4}$ the relative importance of higher quality home health agency selection for patients post-discharge remains to be seen. Likely, the most effective interventions protecting patients in the transient period of increased vulnerability following hospitalization ${ }^{5}$ will be multifaceted.

Conflict of Interest: The author has no conflicts of interest to declare.

Corresponding Author: John M. Thomas, MD; Department of MedicineYale University School of Medicine, New Haven, CT, USA (e-mail:john.thomas@yale.edu).

\section{REFERENCES}

1. Baier et al. A qualitative study of choosing home health care after hospitalization: the unintended consequences of 'patient choice' requirements. J Gen Int Med. 2015. In Press. Doi:10.1007/s11606-014-3164-7.

2. Social Security Administration. Compilation of the Social Security Laws: Free Choice by Patient Guaranteed. Available at: http://www.ssa.gov/OP_ Home/ssact/title18/1802.htm. Accessed 26 Dec 2014.

3. Shepperd et al. Discharge planning from hospital to home. Cochrane Database Syst Rev. 2013, Issue 1. Art. No.: CD000313. Doi:10.1002/ 14651858.CD000313.pub4.

4. Naylor et al. The care span: the importance of transitional care in achieving health care reform. Health Aff. 2011;30(4):746-54.

5. Krumholtz HM. Post-hospital syndrome: an acquired, transient condition of generalized risk. N Engl J Med. 2013;368:100-102. 